\title{
Los límites materiales de la consulta popular en el Ecuador
}

\section{The limits of popular consultation in Ecuador}

Juan Francisco Guerrero del Pozo*

María Victoria Yépez Idrovo**

Recibido / Received: 30/05/2021

Aceptado / Accepted: 30/05/2021

DOI: $10.18272 /$ ulr.v8i2.2324

\section{Citación:}

Guerrero del Pozo, J.F., Yépez Idrovo, M.V. «Los límites materiales de la consulta popular en el Ecuador». USFQ Law Review, Vol 8, no 2, octubre de 2021, pp. 183-211, doi: 10.18272/ulr. v8i2.2324.

* Socio en Durini \& Guerrero Abogados, Quito 170517, Pichincha, Ecuador. Correo electrónico: jfguerrero@dgalegal.com

** Estudiante de la Universidad San Francisco de Quito USFQ, casilla postal 17-1200-841, Quito 170901, Pichincha, Ecuador. Correo electrónico: maria.yepezidrovo@gmail.com ORCID iD: https://orcid.org/0000-0001-9355-5758 


\title{
RESUMEN
}

El presente artículo analiza los límites constitucionales de la consulta popular, reconocida en el artículo 104 de la Constitución ecuatoriana. Para ello, primero se examina la importancia de la consulta popular, para luego identificar algunas de sus desventajas, que nos llevan a cuestionar su eficacia para hacer realidad la participación ciudadana. Posteriormente, se justifica la necesidad de realizar una interpretación sistemática de la Constitución para poder determinar el alcance de la consulta popular y se analizan los límites materiales de este mecanismo de participación, sobre la base de una lectura integral del texto constitucional y de una mirada crítica a la jurisprudencia de la Corte Constitucional.

\section{Palabras Clave}

Consulta popular; límites constitucionales; interpretación sistemática; interpretación constitucional; participación ciudadana; control de constitucionalidad

\begin{abstract}
This article examines the constitutional limits of popular consultation, which is recognized in article 104 of the Ecuadorian Constitution. In order to do so, this paper first addresses the importance of popular consultation as well as some of its disadvantages, which may question its effectiveness as a true mechanism for citizen participation. Subsequently, this article justifies the need for a systematic interpretation of the Constitution in order to determine the scope of popular consultation and analyzes its limits on the basis of a comprehensive reading of the constitutional text and a critical look at the Constitutional Court's jurisprudence.
\end{abstract}

\section{KEYWORDS}

Popular consultation; constitutional limits; systematic interpretation; constitutional interpretation; citizen participation; constitutional control 


\section{INTRODUCCIÓN}

La participación ciudadana es un eje transversal de la Constitución ecuatoriana de 2008 (en adelante CRE). Más allá de reconocer los derechos políticos o "de participación", ${ }^{1}$ la CRE enfatiza en la importancia del derecho a participar en asuntos de interés público al señalar que los ciudadanos "participarán de manera protagónica en la toma de decisiones [...]"2 y al establecer que "[e]n la formulación, ejecución, evaluación y control de las políticas públicas y servicios públicos se garantizará la participación de las personas, comunidades, pueblos y nacionalidades". ${ }^{3}$ Además, en concordancia con la jurisprudencia de la Corte Interamericana de Derechos Humanos (en adelante Corte IDH), que ha establecido que los Estados tienen "la obligación de garantizar medidas positivas, a través de las cuales toda persona que formalmente sea titular de derechos políticos tenga la oportunidad real para ejercerlos", ${ }^{4}$ la CRE reconoce varios mecanismos de participación ciudadana, entre los cuales se encuentra la consulta popular.

A través de la consulta popular - mecanismo de democracia directa que también estaba prevista en la codificación constitucional de 1998- "quien decide finalmente la cuestión planteada, como soberano, es el pueblo". ${ }^{5} \mathrm{Al}$ respecto, se ha sostenido que "la consulta popular puede tener efectos importantes en el desenvolvimiento de una democracia participativa" y que representa una oportunidad para "activar mecanismos para contar con información desde múltiples perspectivas, incorporar a todos los potenciales afectados, debatir, participar y pronunciarse mediante el voto de cada individuo". ${ }^{6}$

Pese a la importancia de la consulta popular para el ejercicio del derecho a participar en asuntos de interés público, ni el artículo 104 de la CRE, que regula la consulta popular, ni las demás normas constitucionales referentes a la participación ciudadana, son claras en cuanto a su alcance. Por esta razón, a través de una interpretación asistemática de la Constitución, se podría llegar a sostener que el derecho a participar en asuntos de interés público a través de la consulta popular es absoluto e ilimitado. Esta interpretación ya ha sido desvirtuada por los dictámenes de la Corte Constitucional — particularmente, por los dictámenes de la actual conformación de la Corte- los cuales han procurado establecer ciertos límites a la consulta popular. Sin embargo, entre

1 La Constitución ecuatoriana de 2008 emplea la denominación "derechos de participación" únicamente en el capítulo quinto del título II. En el resto del texto constitucional se utiliza la denominación "derechos políticos". En este artículo, se utilizarán ambas expresiones indistintamente.

2 Artículo 95, Constitución de la República del Ecuador, R.O. 449, 20 de octubre de 2008.

3 Id., Artículo 85.

4 Caso Castańeda Gutman vs. México, Corte Interamericana de Derechos Humanos, Excepciones Preliminares, Fondo, Reparaciones y Costas, 06 de agosto de 2008, párr. 145.

5 Rafael Oyarte, Derecho Constitucional (Quito: Corporación de Estudios y Publicaciones, 2019), 395.

6 Caso No. 1-20-CP, Corte Constitucional del Ecuador, Voto salvado del juez Ramiro Ávila, 21 de febrero de 2020, párr. 6. 
los jueces de la Corte todavía existen criterios bastante dispares al respecto, expresados en varios votos salvados y concurrentes.

Ante la falta de certeza en cuanto al alcance y límites de la consulta popular, el presente artículo tiene como objetivo determinar a través de una interpretación sistemática de la CRE, cuáles son los límites constitucionales de este mecanismo de democracia directa. Para ello, se definirá y analizará a la consulta popular en el marco de la participación ciudadana en el Ecuador. Posteriormente, se justificará la necesidad de realizar una interpretación sistemática de la Constitución para establecer los límites de la consulta popular y, tras este ejercicio interpretativo, se concluirá que los límites intrínsecos de este mecanismo de participación son (i) los derechos fundamentales; (ii) el régimen de competencias previsto constitucionalmente; y (iii) los demás mecanismos de participación previstos en la CRE, lo cual incluye a los otros tipos de consulta establecidos en la CRE y al propio contenido de la Constitución, que no podrá ser modificado sino por una enmienda, reforma parcial o Asamblea Constituyente. Finalmente, se reflexionará acerca del rol de la Corte Constitucional en el control de constitucionalidad de las consultas populares.

\section{La CONSUlta POPUlar en la Constitución de 2008: ¿MECANISMO PARA HACER REALIDAD LA PARTICIPACIÓN CIUDADANA?}

Previo a analizar si la consulta popular es un mecanismo efectivo de participación ciudadana, es importante definir lo que se debe entender por "participación". Para Juan Pablo Morales, la participación consiste en "el tomar parte en las decisiones del poder que afectan a los ciudadanos y los colectivos en su esfera pública”. ${ }^{7}$ La Corte IDH, por su parte, ha señalado que:

[1]a participación política puede incluir amplias y diversas actividades que las personas realizan individual u organizados, con el propósito de intervenir en la designación de quienes gobernarán un Estado o se encargarán de la dirección de los asuntos públicos, así como influir en la formación de la política estatal a través de mecanismos de participación directa. ${ }^{8}$

De estas definiciones se desprende que la participación ciudadana implica que las personas se involucren - ya sea a través de mecanismos de democracia directa o al elegir a sus representantes- en las decisiones de interés público. ${ }^{9}$ La participación ciudadana conlleva, entonces, el ejercicio de los derechos

7 Juan Pablo Morales Viteri, "Los nuevos horizontes de la participación", en Constitución del 2008 en el contexto andino. Análisis de la doctrina y el derecho comparado, ed. Ramiro Ávila Santamaría (Quito: Ministerio de Justicia y Derechos Humanos, 2008), 158.

8 Caso Yatama vs. Nicaragua, Corte Interamericana de Derechos Humanos, Excepciones Preliminares, Fondo, Reparaciones y Costas, 23 de junio de 2005, párr. 196.

9 Esta concepción de participación está recogida en el artículo 1 de la Constitución de 2008, que prescribe que la soberanía radica en el pueblo y "se ejerce a través de los órganos del poder público y de las formas de participación directa". 
políticos ${ }^{10}$ que están reconocidos en el artículo 61 de la Constitución y entre los cuales se encuentran tanto el derecho a participar en asuntos de interés público como el derecho a ser consultados.

Uno de los mecanismos previstos en la Constitución para el ejercicio de ambos derechos es la consulta popular, que está reconocida en el artículo 104 de la CRE. Esta puede ser solicitada tanto por la ciudadanía como por el Presidente de la República y los gobiernos autónomos descentralizados ${ }^{11}$ y su resultado es "de obligatorio e inmediato cumplimiento". ${ }^{12}$ Si bien la CRE utiliza de manera general el término "consulta popular", la Corte Constitucional ha precisado que esta puede ser de tipo referendo - en cuyo caso se consulta acerca de la aprobación de un texto normativo o propuesta normativa específica- o de tipo plebiscito, en cuyo caso se consulta únicamente acerca de un tema de relevancia pública, sin someter a aprobación de la ciudadanía un texto normativo concreto. ${ }^{13}$

Respecto de la consulta popular, la Corte Constitucional ha señalado que ésta es uno de los "espacios de acción ciudadana, cuyo propósito es la participación material de la sociedad, brindando a los ciudadanos la certidumbre de que no serán excluidos del debate sobre asuntos de interés público". ${ }^{14}$ De ahí que la consulta popular ha sido y es concebida como uno de los mecanismos de participación más importantes y efectivos dentro de nuestro régimen constitucional. Sin embargo, frente a esta concepción utópica e idealista de la consulta popular, es importante mencionar que esta figura también tiene algunos bemoles, que no siempre permiten que sea un mecanismo idóneo para hacer efectiva la participación ciudadana.

En primer lugar, las consultas populares pueden ser utilizadas exclusivamente para que los gobernantes legitimen sus decisiones, sin que exista un real interés por el pronunciamiento de la ciudadanía. Este fenómeno - que es denominado "populismo plebiscitario" por Hernán Salgado ${ }^{15}$ - ha sido muy común a lo largo de la historia. A manera de ejemplo se puede mencionar el plebiscito impulsado por Adolf Hitler para "legitimar" su decisión de anexar Austria (Anschluss) en el año 1938. Esta consulta popular fue descrita por Hitler como "un verdadero plebiscito" para decidir sobre el futuro y el destino de

10 Los derechos políticos han sido entendidos como "aquellos que reconocen y protegen el derecho y el deber de todos los ciudadanos de participar en la vida política de su país". Informe de la Comisión Interamericana de Derechos Humanos sobre la democracia y derechos humanos en Venezuela 2009, Informe, Comisión Interamericana de Derechos Humanos 2009, OEA/Ser.L/V/II, Doc.54, 30 de diciembre de 2009, capítulo II, párr. 18.

11 Adicionalmente, el artículo 407 de la Constitución prevé que, excepcionalmente, la Asamblea Nacional podría convocar a consulta popular si lo estima conveniente en el caso de que sea de interés nacional explotar los recursos no renovables que se encuentran en áreas protegidas y zonas intangibles.

12 Artículo 106, Constitución de la República del Ecuador.

13 Dictamen No. 2-19-CP/19, Corte Constitucional del Ecuador, 20 de junio de 2019, párr. 29

14 Dictamen No. 1-20-CP/20, Corte Constitucional del Ecuador, 21 de febrero de 2020, párr. 16-17.

15 Hernán Salgado Pesantes, Lecciones de Derecho Constitucional, (Quito: Ediciones Legales S.A., 2012), 112. 
Austria. Tras una importante campaña de manipulación mediática —incluso se prohibió a los periódicos utilizar la palabra ja (sí) en otro contexto que no fuera para referirse a la consulta popular- el 10 de abril de 1938, el "Sí" al Anschluss obtuvo un $99.08 \%$ en el "antiguo Reich" (Alemania) y un $99.75 \%$ en Austria. ${ }^{16}$

En segundo lugar y en el mismo orden de ideas, la consulta popular puede reducirse a un voto emocional que se fundamente en la confianza - o desconfianza- de las personas en el régimen de turno. Un ejemplo de lo mencionado se encuentra en la consulta popular promovida en el ańo 1986 por el entonces Presidente de la República León Febres Cordero. En esta consulta popular, se buscaba un pronunciamiento de la ciudadanía acerca de si estaba de acuerdo con que los ciudadanos que no estaban afiliados a un partido político puedan ser elegidos. La campaña en contra de la consulta popular fue "Dile No a León" y, finalmente, el "No" se impuso. Sobre esta consulta, se ha dicho que "[e]l electorado no votó por una tesis", sino que "votó contra un Gobierno", ${ }^{17}$ lo cual refleja que — en ciertas ocasiones — la consulta popular puede limitarse a expresar el apoyo o el rechazo al proponente, sin ser un verdadero instrumento mediante el cual la ciudadanía emite un pronunciamiento de fondo sobre un asunto de interés público.

En tercer lugar, también se ha criticado a la consulta popular por considerar que la ciudadanía no está en capacidad de decidir sobre cualquier asunto. Por ejemplo, Rafael Oyarte, recogiendo el criterio de Bobbio, señala que "[c]onsultar aspectos de carácter científico o técnico a la ciudadanía implica someter a decisión popular asuntos que deben ser resueltos por expertos y no por una mera expresión mayoritaria”. ${ }^{18}$ Esta crítica es quizás matizada por la jurisprudencia de la Corte Constitucional, que ha desarrollado parámetros para que se garantice la libertad del elector, ${ }^{19}$ incluso cuando la consulta popular trata asuntos técnicos. Así, la Corte ha señalado que no se garantiza la libertad del elector si la pregunta que se busca someter a consulta popular contiene términos técnicos que no están debidamente contextualizados y explicados para que el elector los comprenda y tome una decisión informada. ${ }^{20}$ Por lo tanto, en caso de que los considerandos introductorios no presenten la información básica que el elector requiera para poder decidir libremente incluso acerca de

16 Ian Kershaw, Hitler. La biografia definitiva (Barcelona: Ediciones Península, 2010), 547-551.

17 Luis Verdesoto Salgado, "El Ecuador y la propuesta de reforma constitucional de 1986 (La consulta popular de junio. Una respuesta política frente a una cuestión jurídico-constitucional)", en Estudios en homenaje al doctor Héctor Fix-Zamudio en sus treinta años como investigador de las ciencias jurídicas t.I ed. Instituto de Investigaciones Jurídicas de la Universidad Autónoma de México (México: Universidad Autónoma de México, 1988), 859. https://archivos.juridicas.unam.mx/www/ bjv/libros/2/641/39.pdf

18 Rafael Oyarte, Derecho Constitucional, 395.

19 Dictamen No. 9-19-CP/19, Corte Constitucional del Ecuador, 17 de septiembre de 2019, párr. 48: La plena libertad del elector implica que la "presentación [de los textos introductorios, considerandos y preguntas sometidos a consulta popular] debe garantizar el derecho de los electores a formarse una opinión razonablemente objetiva y a expresar libremente esa opinión en el proceso eleccionario".

20 Dictamen No. 7-20-CP/21, Corte Constitucional del Ecuador, 27 de enero de 2021, párr. 108. 
un asunto técnico, la solicitud de consulta popular no superará el control de constitucionalidad. ${ }^{21}$

De todo lo expuesto se puede concluir que si bien la consulta popular se perfila como un mecanismo de participación muy poderoso que permite que la ciudadanía ejerza su derecho a participar en asuntos de interés público, también debe ser utilizada con mucha cautela, con el fin de no convertirse en una herramienta que sirva exclusivamente para fines políticos. Adicionalmente - y como se profundizará más adelante en este trabajo — se puede observar cómo el control de constitucionalidad al que está llamada a realizar la Corte Constitucional, permite contrarrestar algunos de los bemoles que presenta este importante mecanismo de participación ciudadana.

\section{LOS LÍMITES CONSTITUCIONALES DE LA CONSULTA POPULAR}

\subsection{NECESIDAD DE UNA INTERPRETACIÓN SISTEMÁTICA DEL ARTÍ́CUlo 104 de la CONSTITUCIÓN}

Una vez que se ha definido a la consulta popular y se ha hecho hincapié en la importancia de la participación ciudadana en el Ecuador, se determinará el alcance de este mecanismo de participación de acuerdo con la Constitución de 2008.

Como quedó señalado, la consulta popular está reconocida en el artículo 104 de la Constitución. Esta norma prescribe:

El organismo electoral correspondiente convocará a consulta popular por disposición de la Presidenta o Presidente de la República, de la máxima autoridad de los gobiernos autónomos descentralizados o de la iniciativa ciudadana.

La Presidenta o Presidente de la República dispondrá al Consejo Nacional Electoral que convoque a consulta popular sobre los asuntos que estime convenientes.

Los gobiernos autónomos descentralizados, con la decisión de las tres cuartas partes de sus integrantes, podrán solicitar la convocatoria a consulta popular sobre temas de interés para su jurisdicción.

21 Pese a la importancia de los considerandos, cabe preguntarse si estos son realmente de conocimiento y acceso de la ciudadanía. En la campaña electoral, no todos los electores se informarán minuciosamente acerca de los considerandos o justificaciones de las preguntas sometidas a consulta. Al momento de sufragar, los votantes tampoco tienen acceso a los considerandos de las preguntas. De hecho, estos suelen ser muy numerosos (en la consulta popular de Cuenca realizada el 7 de febrero de 2021, por ejemplo, fueron 67) y sería poco práctico que cada elector deba recibir toda esta información al momento de votar. Seguramente por estas dificultades y para que la ciudadanía tenga claros los efectos de la consulta popular, la Corte Constitucional, justamente en el caso de la consulta de Cuenca, dispuso que se incluya en el texto del cuestionario que las prohibiciones mencionadas en las preguntas se refieren "a lo indicado en los considerandos 65 y 66 " y que cualquier medida adoptada regirá hacia el futuro. Esta aclaración podría haber ayudado a las personas a remitirse a estos considerandos previo a decidir, pero tampoco garantiza totalmente la libertad de los electores ni la toma de decisiones completamente informadas. 
La ciudadanía podrá solicitar la convocatoria a consulta popular sobre cualquier asunto. Cuando la consulta sea de carácter nacional, el petitorio contará con el respaldo de un número no inferior al cinco por ciento de personas inscritas en el registro electoral; cuando sea de carácter local el respaldo será de un número no inferior al diez por ciento del correspondiente registro electoral.

Cuando la consulta sea solicitada por ecuatorianas y ecuatorianos en el exterior, para asuntos de su interés y relacionados con el Estado ecuatoriano, requerirá el respaldo de un número no inferior al cinco por ciento de las personas inscritas en el registro electoral de la circunscripción especial.

Las consultas populares que soliciten los gobiernos autónomos descentralizados o la ciudadanía no podrán referirse a asuntos relativos a tributos o a la organización político administrativa del país, salvo lo dispuesto en la Constitución.

En todos los casos, se requerirá dictamen previo de la Corte Constitucional sobre la constitucionalidad de las preguntas propuestas (énfasis ańadido).

La norma constitucional transcrita le da un amplio alcance a la consulta popular. En el caso de la iniciativa ciudadana, por ejemplo, parece claro que se buscó favorecer el ejercicio de los derechos de participación al establecer que se podrá consultar sobre "cualquier asunto". De acuerdo con esta norma, parecería que los únicos límites claros a la consulta popular son los asuntos tributarios y la organización político administrativa del país, en el caso de las consultas promovidas por los gobiernos autónomos descentralizados y la ciudadanía, y el control de constitucionalidad realizado por la Corte Constitucional, en todos los casos.

Sin embargo, interpretar y determinar el alcance del artículo 104 de la CRE de manera aislada y con base exclusivamente en el método de interpretación literal es insuficiente. ¿Cuál es, realmente, el alcance de la expresión "cualquier asunto"? ¿Existen otras disposiciones dentro del texto constitucional que representan límites para la consulta popular? ¿Qué temas pueden ser considerados "de interés" para la jurisdicción de los gobiernos autónomos descentralizados? Son las respuestas a estas preguntas las que, en nuestro criterio, marcan los límites de la consulta popular, que deberán ser tomados en consideración por la Corte Constitucional al realizar el control previo de constitucionalidad de las solicitudes de consulta popular.

Ahora bien, para dar una respuesta a las interrogantes planteadas y determinar el alcance del artículo 104 de la Constitución, es fundamental recurrir a una interpretación sistemática, es decir, a un análisis integral del texto constitucional. Este método de interpretación, que implica que ninguna norma constitucional debe quedar vacía de contenido, está previsto en el artículo 427 de la CRE y, junto al método gramatical o literal, es al que el intérprete debe recurrir en un primer momento. Solo en caso de duda, según el mismo artícu- 
lo 427, se podrá recurrir a otros métodos de interpretación, como el principio pro homine o el método teleológico. ${ }^{22}$

En el caso de la consulta popular, la propia Corte Constitucional ha reconocido la necesidad de realizar una interpretación sistemática del artículo 104 de la Constitución. Al referirse al alcance de la expresión "cualquier asunto" contenida en dicha norma, la Corte ha señalado lo siguiente:

[L]a Constitución de la República debe ser leída y aplicada de manera sistemática, pues el sentido de las normas de la Constitución tendrá que ajustarse a la integralidad de su texto.

Bajo estas consideraciones, si bien es cierto que el artículo 104 de la Constitución de la República, en su parte pertinente dispone, que: "La ciudadanía podrá solicitar la convocatoria a consulta popular sobre cualquier asunto", aquello no significa que esta potestad sea absoluta y, al contrario, encuentra sus límites en el propio texto constitucional, por lo que se requiere una lectura integral y sistemática de la Norma Fundamental para comprender los casos en los cuales la consulta popular prevista en el artículo 104, no procede (énfasis añadido). ${ }^{23}$

En similar sentido, la Corte Constitucional ha sostenido que los límites a la consulta popular — que deberán ser analizados al realizar el control previo de constitucionalidad de las consultas populares- "pueden estar contenidos en el propio texto constitucional o en otras fuentes que se integran a la Constitución a través del bloque de constitucionalidad" (énfasis añadido). ${ }^{24}$

De lo expuesto queda claro que el artículo 104 de la Constitución no puede ser leído de manera aislada, sino que debe guardar armonía con el resto del texto constitucional, y que la consulta popular tiene ciertos límites que se desprenden de la propia CRE. Es sobre la base de esta interpretación sistemática de la Constitución que, a continuación, se analizarán los límites que consideramos intrínsecos a la consulta popular: (i) los derechos fundamentales; (ii) el régimen de competencias previsto constitucionalmente; y, (iii) los otros procedimientos previstos en la CRE, lo cual incluye a los otros tipos de consulta establecidos en la CRE y al propio contenido de la Constitución, que no podrá ser modificado sino por una enmienda, reforma parcial o Asamblea Constituyente.

22 Art. 427.- "Las normas constitucionales se interpretarán por el tenor literal que más se ajuste a la Constitución en su integralidad. En caso de duda, se interpretarán en el sentido que más favorezca a la plena vigencia de los derechos y que mejor respete la voluntad del constituyente, y de acuerdo con los principios generales de la interpretación constitucional".

23 Dictamen No. 6-19-CP/19, Corte Constitucional del Ecuador, 01 de agosto de 2019, párr. 29-30.

24 Dictamen No. 4-19-CP/19, Corte Constitucional del Ecuador, 01 de agosto de 2019, párr. 12. 


\subsection{LOS DERECHOS FUNDAMENTALES: UN LÍMITE INSTRÍNSECO A LA REGLA DE LA MAYORÍA}

Es muy común escuchar que "los derechos fundamentales no se consultan". Esta afirmación encuentra su sustento en el concepto mismo de "derechos fundamentales", ${ }^{25}$ los cuales se derivan de la dignidad humana y, por lo tanto, son inalienables, irrenunciables y están fuera del alcance de cualquier autoridad pública y de cualquier persona en general. En ese sentido, el juez Alí Lozada, en su voto concurrente dentro del caso No. 73-09-IN/21, señaló que "[n] o todo derecho subjetivo es un derecho fundamental", pues estos "envuelven bienes morales básicos de los que no puede privarse a los individuos o colectivos". ${ }^{26}$ Asimismo, la Corte Constitucional ha sido clara en cuanto a que los derechos fundamentales tienen su fuente en la dignidad humana, al establecer que "[n]uestra Constitución reconoce, desde su preámbulo, el respeto por la dignidad de las personas y colectividades" y que "[e]n tal sentido, el artículo 11 numeral 7 es claro al señalar que los derechos se derivan de la dignidad de las personas, pueblos, comunidades y nacionalidades" y son "límites al poder del Estado, que está llamado a respetarlos y protegerlos". ${ }^{27}$ Dado que los derechos fundamentales preexisten al Estado, son límites al poder y se derivan de la dignidad humana, es claro que no pueden ser anulados por el Estado, ni tampoco por la ciudadanía a través de una consulta popular.

En este sentido, la jurisprudencia constitucional e interamericana ha sido consistente en cuanto a que la protección de los derechos fundamentales constituye un límite intrínseco a lo que puede ser objeto de decisión de una mayoría y, por lo tanto, materia de una consulta popular. Al respecto, la Corte Constitucional ha sostenido que:

[E]n un Estado constitucional, la democracia no puede entenderse basada únicamente en la regla de la mayoría, sino que, más bien, los derechos fundamentales constituyen los presupuestos del proceso político democrático. Si aquellos no se respetan, la democracia puede acabar por devorarse a sí misma: usando un ejemplo exagerado pero ilustrativo, imaginemos una sociedad en la que la mayoría de individuos decide, por votación, privar del derecho al voto a los individuos de la minoría (énfasis ańadido). ${ }^{28}$

En el mismo sentido, la Corte IDH ha señalado que "la protección de los derechos humanos constituye un límite infranqueable a la regla de mayorías,

25 A lo largo de este trabajo, se utilizarán las expresiones "derechos fundamentales" y "derechos constitucionales" como sinónimos. Sin perjuicio de ello, nos parece más apropiada la denominación "derechos fundamentales", pues esta no hace referencia al listado de derechos contenido en un texto particular, sino a los derechos que se derivan de la dignidad humana.

26 Caso No. 73-09-IN, Corte Constitucional del Ecuador, 03 de marzo de 2021, Voto concurrente del juez Alí Lozada Prado, párr. 3.

27 Sentencia No. 282-13-JP/19, Corte Constitucional del Ecuador, 04 de septiembre de 2019, párr. 30. En similar sentido, ver Hernán Salgado Pesantes, Lecciones de Derecho Constitucional, 63-64.

28 Dictamen No. 11-19-CP/19, Corte Constitucional del Ecuador, 04 de diciembre de 2019, párr. 20.2. 
es decir, a la esfera de lo 'susceptible de ser decidido’ por parte de las mayorías en instancias democráticas" ${ }^{29}$

De lo mencionado queda claro que la participación democrática en ningún caso puede entenderse como absoluta, pues siempre encontrará sus límites en los derechos fundamentales de las personas. El control previo de constitucionalidad de las consultas populares que realiza la Corte Constitucional es justamente un mecanismo para velar por el respeto de este límite a la consulta popular. ${ }^{30}$ Por ello, la Corte ha señalado que este organismo "tiene la última palabra" para proteger los derechos fundamentales —incluso si sus fallos "van en contravía de lo que la mayoría democrática podría opinar"31_ lo cual evidencia que el control de constitucionalidad es un mecanismo contramayoritario que busca proteger los derechos de las minorías frente a la decisión de la mayoría. De no ser así —y si no existieran mecanismos como el control de constitucionalidad de las consultas populares para controlar que estas no menoscaben los derechos fundamentales - podría existir una democracia plebiscitaria, en la que "el consenso de la mayoría legitima cualquier abuso", 32 incluyendo las vulneraciones a los derechos de las personas.

\subsubsection{AlCANCE DEL LÍMITE A La CONSUlTa POPUlaR MARCADO POR LOS DERECHOS FUNDAMENTALES}

Sin perjuicio de lo señalado, cabe mencionar que existe una discusión sobre el alcance del límite que imponen los derechos a la consulta popular. Respecto de la posibilidad de realizar consultas populares sobre derechos constitucionales, es interesante mencionar el criterio del juez Ramiro Ávila expresado en su voto salvado dentro del caso No. 1-20-CP:

La Constitución, en el artículo 104, establece que "La ciudadanía podrá solicitar la convocatoria a consulta popular sobre cualquier asunto"'. Desde una primera lectura, la Constitución permite consultar a la ciudadanía sobre cualquier tema. Sin embargo uno de los límites para permitir una consulta popular es la restricción, limitación o anulación de derechos. Se suele decir, y con mucha razón, que el reconocimiento de los derechos no se consulta. Efectivamente, en algunos casos, como los que tienen que ver con prohibiciones del tipo no permitir la

29 Caso Gelman vs. Uruguay, Corte Interamericana de Derechos Humanos, Excepciones Preliminares, Fondo, Reparaciones y Costas, 24 de febrero de 2005, párr. 239.

30 Por ejemplo, frente a una solicitud de consulta popular que incluía aspectos como la inclusión de la pena de muerte y de la cadena perpetua para ciertos delitos - y que contenía términos despectivos respecto de las personas que cometieran dichos delitos—, la Corte Constitucional señaló que: "Esta Corte Constitucional recuerda que su función frente a las propuestas de consultas populares, precisamente, es garantizar que las personas no menoscaben el orden constitucional y, por tanto, protejan los derechos de la ciudadanía" (énfasis añadido). Dictamen No. 14-19-CP/19, Corte Constitucional del Ecuador, 07 de noviembre de 2019, párr. 21.

31 Dictamen No. 11-19-CP/19, Corte Constitucional del Ecuador, 04 de diciembre de 2019, párr. 20.1.

32 Luigi Ferrajoli, Democracia y Garantismo (Madrid: Editorial Trotta, 2010), 25, citado en Esteban Javier Polo Pazmiño, "El ámbito del control constitucional sobre la convocatoria a consulta popular en el Ecuador", Revista Ecuatoriana de Derecho Constitucional Ańo II, no.2 (Abril 2018): 78. 
pena de muerte, la tortura, la discriminación, la sanción sin debido proceso, la consulta es absolutamente vedada. Algún día, cuando tomemos en serio los derechos de la naturaleza y las protecciones jurídicas sean eficaces, ojalá podamos poner a los derechos de la naturaleza en esta categoría de derechos que no se pueden consultar porque está prohibida su vulneración.

Hay otros casos en los que ciertos derechos tienen un margen de apreciación para su aplicación y que pueden admitir restricciones justificadas, entre los que están los derechos patrimoniales (que si no se limitan llegan a la exclusión injustificada), ciertos derechos de participación (que si no se limitan llegan al autoritarismo) y los derechos de libertad relacionados con el mercado (que si no se limitan llegan al monopolio u oligopolio). En estos casos cabe la ponderación, la libertad de configuración legislativa y evidentemente la consulta popular (énfasis añadido). ${ }^{33}$

Esta posición, si bien reconoce que los derechos constituyen límites a lo que puede ser objeto de una consulta popular, sostiene, a su vez, que este límite no siempre es aplicable. En este sentido, el citado juez realiza una distinción entre los derechos que podrían, o no, ser materia de una consulta popular y considera que ciertos derechos, como los "de libertad relacionados con el mercado", sí podrían ser restringidos a través de este mecanismo de participación. Esta categorización de derechos es cuestionable, pues todos los derechos reconocidos en la Constitución son de igual jerarquía, independientemente de si, por ejemplo, algunos tienen implicaciones patrimoniales. ${ }^{34}$ Por lo tanto, la CRE impide que el límite que los derechos imponen a la consulta popular esté marcado por la "clase" o "categoría” de derecho de que se trate, como lo ha sostenido el juez Ávila.

En nuestro criterio, aquello que determinará tanto el alcance de la libertad de configuración legislativa como de la consulta popular, es el contenido esencial de los derechos. Por lo tanto, consideramos que se podrá regular el ejercicio de los derechos y garantías constitucionales a través de una consulta popular siempre que no se afecte el contenido esencial del derecho fundamental en cuestión. ${ }^{35}$ Para desarrollar esta tesis, analizaremos (i) el concepto de "contenido esencial" de los derechos; (ii) cómo este concepto impone un límite a la libertad de configuración legislativa; y (iii) por qué consideramos que este límite es igualmente aplicable a la consulta popular.

33 Dictamen No. 1-20-CP/20, Corte Constitucional del Ecuador, Voto salvado del juez Ramiro Ávila, 21 de febrero de 2020, párr. 3-4.

34 Artículo 11 numeral 6, Constitución de la República del Ecuador.

35 No coincidimos con el juez Ávila en cuanto a que la consulta popular puede establecer "restricciones justificadas" a los derechos fundamentales, pues la Corte Constitucional ha señalado que una restricción es siempre una limitación injustificada a un derecho o garantía. Al respecto, ver Dictamen No. 4-19-RC/19, Corte Constitucional del Ecuador, 21 de agosto de 2019, párr. 14-15. Por ello, nos referiremos a las "limitaciones justificadas" al ejercicio de los derechos o a la "regulación" del ejercicio de los derechos. 
Respecto de la definición de "contenido esencial" de los derechos fundamentales, Parejo Alfonso señala que este "no es otra cosa que el reducto último que compone la sustancia del derecho, disuelto el cual (aunque solo sea en alguno de sus elementos) el derecho deja de ser aquello a lo que la norma fundamental se refiere". ${ }^{36}$ También se ha sostenido que el contenido o núcleo esencial de los derechos - metafóricamente hablando - consiste en "aquella parte [del derecho] que resulta definitoria o identificadora del significado que un derecho tiene en nuestra cultura jurídica, y cuyo sacrificio lo desnaturalizaría". ${ }^{37}$ De ambas definiciones se desprende que el contenido esencial de los derechos (i) es aquello que permite reconocer a un derecho fundamental como tal y (ii) no puede ser alterado, so pena de desnaturalizar al derecho. Por ello, se ha afirmado que el contenido esencial es una barrera al poder del legislador para limitar los derechos ${ }^{38}$ que, de ser superada, implica la anulación y desnaturalización del derecho. ${ }^{39}$

A diferencia de la jurisprudencia comparada ${ }^{40}$ la Corte Constitucional ecuatoriana no ha desarrollado líneas jurisprudenciales sólidas en torno al concepto de "contenido esencial" de los derechos. ${ }^{41} \mathrm{~A}$ pesar de ello, al analizar los principios contenidos en los numerales 4 y 8 del artículo 11 de la Constitución, ${ }^{42}$ la Corte Constitucional sí ha señalado que:

De acuerdo con ambos principios, el estatus de protección que brindan los derechos reconocidos en la Norma Suprema no puede estar sujeto a limitaciones sin una justificación que esté basada en la satisfacción de otro derecho constitucional, y que se lo haga en razón de la proporcionalidad,

36 Luciano José Parejo Alfonso, "El contenido esencial de los derechos fundamentales en la jurisprudencia constitucional; a propósito de la sentencia del Tribunal Constitucional de 8 de abril de 1981", Revista Española de Derecho Constitucional Vol. 1 Núm. 3 (Septiembre-diciembre 1981), 180.

37 Luis Prieto Sanchís, Justicia constitucional y derechos fundamentales (Madrid: Trotta, 2003), 232.

38 Humberto Nogueira Alcalá, "Aspectos de una Teoría de los Derechos Fundamentales: La Delimitación, Regulación, Garantías y Limitaciones de los Derechos Fundamentales", Ius et Praxis Vol. 11 no. 2. (2005), 15-64. https://dx.doi.org/10.4067/ S0718-00122005000200002

39 Sobre cómo determinar el contenido esencial de los derechos, se han desarrollado algunas teorías, cuyo análisis escapa el alcance de este trabajo. Al respecto, ver Humberto Nogueira Alcalá, "Aspectos de una Teoría de los Derechos Fundamentales: La Delimitación, Regulación, Garantías y Limitaciones de los Derechos Fundamentales”, 15-64. Para un análisis del caso ecuatoriano, es recomendable ver Sebastián López Hidalgo, "Configuración de los derechos fundamentales y su contenido esencial en el constitucionalismo ecuatoriano", Cuestiones Constitucionales Revista Mexicana de Derecho Constitucional Núm. 41 (Julio-diciembre 2019).

40 Ver, por ejemplo, Sentencia No. T-426/92, Corte Constitucional de Colombia, 24 de junio de 1992. Asimismo, ver la jurisprudencia espańola desarrollada a partir de la Sentencia 11/1981 del Tribunal Constitucional de Espańa, de fecha 08 de abril de 1981.

41 Respecto de algunos criterios que la Corte Constitucional ha emitido acerca del contenido o núcleo esencial de los derechos, ver Sentencia No. 009-10-SIN-CC, Corte Constitucional del Ecuador, 09 de septiembre del 2010, p. 33. En esta sentencia, la Corte se refirió al núcleo esencial del derecho al trabajo. Ver también Sentencia No. 012-09-SEP-CC, Corte Constitucional del Ecuador, 14 de julio de 2009, p. 19-21; Sentencia No. 036-15-SEP-CC, Corte Constitucional del Ecuador, 11 de febrero de 2015, p. 8; y, Sentencia No. 002-18-SIN-CC, Corte Constitucional del Ecuador, 21 de marzo de 2018, p. 64.

$42 \mathrm{El}$ artículo 11 numeral 4 de la CRE prescribe que "ninguna norma jurídica podrá restringir el contenido de los derechos ni de las garantías constitucionales". El numeral 8 del artículo 11 establece que "será inconstitucional cualquier acción u omisión de carácter regresivo que disminuya, menoscabe o anule injustificadamente el ejercicio de los derechos”. 


\section{sin llegar al extremo de desnaturalizar el contenido del derecho limi- tado (énfasis añadido). ${ }^{43}$}

Asimismo, la Corte ha establecido que la libertad de configuración legislativa no es absoluta, pues debe "circunscribirse a determinar aspectos de la esfera de la legalidad" 44 y ejercerse "en respeto a los derechos constitucionales de las personas, no siendo posible que estos sean vaciados de contenido" (énfasis añadido). ${ }^{45}$ Por su parte, Hernán Salgado ha sostenido que puede regularse y limitarse el ejercicio de los derechos, mas no se puede restringir su contenido, pues aquello "significaría desnaturalizar la esencia misma del derecho humano" ${ }^{46}$ De lo señalado, queda claro que el legislador tiene libertad para limitar el ejercicio de los derechos constitucionales, siempre que dicha limitación sea proporcional. ${ }^{47}$ Sin embargo, cualquier actuación del legislador para regular el ejercicio de los derechos fundamentales tendrá su límite en el contenido esencial del derecho, de manera que este no sea anulado ni desnaturalizado.

Previo a determinar si este límite a la libertad de configuración legislativa es aplicable también a la consulta popular, es necesario analizar si una consulta popular puede regular el ejercicio de los derechos constitucionales, considerando que la CRE prevé una reserva de ley orgánica ${ }^{48}$ para el efecto.

En nuestro criterio, los temas que deben ser regulados a través de ley orgánica, no están excluidos de una eventual consulta popular, por las siguientes razones: (i) la esencia del principio de reserva legal está garantizada mediante la consulta popular y (ii) en todo caso - y ante la falta de un pronunciamiento concluyente por parte de la Corte Constitucional — no cabe realizar una interpretación restrictiva, que dada la amplitud de materias contenidas en las reservas legales previstas en la CRE, le restaría eficacia a la consulta popular.

Uno de los argumentos que sustenta la reserva de ley para la regulación y limitación de derechos y que fue empleado por la Corte IDH en su Opinión Consultiva OC-6/86, es que además de que una ley representa la voluntad popular, el procedimiento legislativo "permite a las minorías expresar su inconformidad, proponer iniciativas distintas, participar en la formación de la voluntad política o influir sobre la opinión pública para evitar que la mayoría actúe arbitrariamente" ${ }^{49}$ La Corte Constitucional, por su parte, ha sosteni-

43 Sentencia No. 006-15-SCN-CC, Corte Constitucional del Ecuador, 27 de mayo de 2015, p. 16. Este fallo fue citado en la Sentencia No. 7-15-IN/21, Corte Constitucional del Ecuador, 07 de abril de 2021, párr. 28.

44 Sentencia No. 34-19-IN/21 y acumulados, Corte Constitucional del Ecuador, 28 de abril de 2021, párr. 100.

45 Ibid., párr. 104.

46 Hernán Salgado Pesantes, Lecciones de Derecho Constitucional, 72.

47 Para ello, se deberá recurrir al principio de proporcionalidad, recogido en el artículo 3 numeral 2 de la Ley Orgánica de Garantías Jurisdiccionales y Control Constitucional (en adelante LOGJCC).

48 Artículo 133 numeral 2, Constitución de la República del Ecuador.

49 Opinión Consultiva OC-6/86, Corte Interamericana de Derechos Humanos, 9 de mayo de 1986, párr. 22. 
do que el principio de reserva de ley permite "definir y regular las materias de especial importancia a través de debates plurales y transparentes dotados de legitimidad". ${ }^{50} \mathrm{La}$ CRE ha buscado reforzar estos elementos característicos de la reserva legal en el caso de la regulación de los derechos y garantías constitucionales al establecer una reserva de ley orgánica, que requiere de un procedimiento, en teoría, ${ }^{51}$ más riguroso (mayoría absoluta de los miembros de la Asamblea Nacional) para su aprobación, derogación, reforma e interpretación. ${ }^{52}$

Si bien es cierto que la consulta popular no genera, al menos formalmente, el grado de debate y deliberación democrática que sí conlleva el procedimiento legislativo y puede estar sujeta a las desventajas que se identificaron al inicio de este artículo, lo que busca resguardar la reserva legal, según los criterios expuestos, es la representación de la voluntad popular y la protección de los derechos de las minorías. En el caso de las consultas populares, es evidente que la primera exigencia se cumple, pues el pueblo se pronunciaría directamente, sin necesidad de la intervención del órgano representativo. De hecho, cabe recalcar que de acuerdo con el artículo 106 de la CRE, la consulta popular se aprueba con la mayoría absoluta de los votos válidos, ${ }^{53}$ por lo que también se cumple el requisito de respaldo y legitimidad de la decisión que busca la reserva de ley orgánica. En cuanto a la protección de los derechos de las minorías, esta es garantizada, como se señaló anteriormente, a través del control previo de constitucionalidad de las solicitudes de consulta popular que realiza la Corte Constitucional. Por lo tanto, tampoco desde este punto de vista cabría sostener, de manera categórica, que no se puede regular el ejercicio de los derechos y garantías a través de una consulta popular.

Por otro lado, es importante recalcar que la CRE, así como establece una reserva de ley orgánica, también contempla la posibilidad de que la ciudadanía convoque a consulta popular "sobre cualquier asunto", lo cual abarca tanto la aprobación de un texto normativo o propuesta normativa cuando la consulta es de tipo referendo, como la necesidad de legislar sobre una determinada materia cuando se trata de un plebiscito. ${ }^{54}$ Sostener que la reserva de ley orgánica impide per se que se regule el ejercicio de los derechos a través de una consulta popular — sin que la Constitución excluya expresamente dicha materia del alcance de la consulta popular, como sí lo hace en el caso de asuntos tributarios, por ejemplo- implicaría realizar una interpretación restrictiva en cuanto al

50 Sentencia No. 002-14-SIN-CC, Corte Constitucional del Ecuador, 14 de agosto de 2014, p. 40.

51 En el Ecuador, tal rigurosidad se ha desvanecido, pues, de acuerdo con el artículo 9 numeral 6 de la Ley Orgánica de la Función Legislativa, la ley ordinaria requiere la misma mayoría.

52 Artículo 133, Constitución de la República del Ecuador.

53 Artículo 106, Constitución de la República del Ecuador. Sin embargo, el artículo 198 del Código de la Democracia prescribe que "para la aprobación de un asunto en referéndum o consulta popular se requerirá al menos la mitad más uno de los votos válidos emitidos".

54 Dictamen No. 2-19-CP/19, Corte Constitucional del Ecuador, 20 de junio de 2019, párr. 29. 
alcance de la consulta popular. Esta interpretación contraviene el principio pro homine, reconocido en el artículo 11 numeral 5 de la CRE así como en el artículo 427, que lo recoge como método de interpretación que debe aplicarse en caso de duda sobre el alcance de una norma constitucional.

Justamente existe duda sobre el alcance de la reserva legal y la consulta popular porque la jurisprudencia de la Corte Constitucional no ha sido clara respecto de la relación entre ambas figuras. En un dictamen del año 2019, la Corte estableció que la consulta popular no puede servir para eludir el procedimiento establecido para la iniciativa popular normativa, ${ }^{55}$ es decir, para eludir el procedimiento previsto para que la ciudadanía proponga la creación, reforma o derogatoria de normas jurídicas. ${ }^{56}$ En cambio, en un dictamen del año 2021 la Corte señaló que la existencia de la iniciativa popular normativa no impide per se que se sometan reformas legales a consideración de la ciudadanía mediante una consulta popular. ${ }^{57}$ Sin embargo, en este mismo dictamen del ańo 2021, al analizar la posibilidad de realizar una consulta popular sobre asuntos penales, la Corte señaló que el hecho de que "la consulta popular no permite el debate en sede parlamentaria [...] puede incidir en la constitucionalidad de utilizar este mecanismo para la adopción de nuevos tipos penales o el aumento de las penas previstas para los tipos ya existentes" ${ }^{58}$ Este criterio - fundamentado en la falta de debate parlamentario en la consulta popular- es bastante amplio y podría llevar a que se excluya del ámbito de la consulta popular a todas aquellas materias incluidas en la reserva de ley, sin que exista una exclusión constitucional expresa en ese sentido - como sí existe en el caso de otras materias - restándole eficacia a la consulta popular.

Pese a la falta de claridad por parte de la jurisprudencia constitucional, consideramos que, por los argumentos expuestos, la existencia de la reserva de ley orgánica no excluye la posibilidad de regular el ejercicio de los derechos y garantías constitucionales, vía una consulta popular. Al igual que en el caso de la libertad de configuración legislativa, el contenido esencial de los derechos fundamentales marcará el límite de lo que podrá ser objeto de pronunciamiento por parte de la ciudadanía. En todos los casos, le corresponderá a la Corte Constitucional realizar un estricto control de constitucionalidad de las solicitudes de consulta popular, mediante el cual examine el fondo de las preguntas $\mathrm{y}$ verifique que estas no anulen el contenido de un derecho fundamental.

55 Dictamen No. 12-19-CP/19, Corte Constitucional del Ecuador, 25 de septiembre de 2019, párr. 23 b).

56 Artículo 103, Constitución de la República del Ecuador.

57 Dictamen No. 7-20-CP/21, Corte Constitucional del Ecuador, 27 de enero de 2021, párr. 194.

58 Ibid., párr. 42. 


\subsection{LA CONSULTA POPULAR DEBE RESPETAR EL RÉGIMEN DE COMPETENCIAS PREVISTO EN LA CONSTITUCIÓN}

De acuerdo con el artículo 104 de la CRE, los gobiernos autónomos descentralizados están facultados para convocar a consulta popular "sobre temas de interés para su jurisdicción”. Para guardar armonía con el resto del texto constitucional, esta frase debe ser interpretada de manera que se respete el régimen de competencias establecido en la Constitución, ${ }^{59}$ mediante el cual la CRE asigna competencias exclusivas y excluyentes a cada nivel de gobierno.

Al respecto, Rafael Oyarte señala que con el régimen de competencias "se excluye que se consulte a nivel seccional asuntos que superen los intereses de esa sección territorial, esto es, que atinjan a otras localidades o que sean de interés nacional", ${ }^{60}$ pues, en ese caso, se estaría excluyendo injustificadamente a un grupo de personas de un proceso democrático en el que tienen derecho a pronunciarse. De la misma manera, se excluye que un asunto de competencia exclusiva de un gobierno autónomo descentralizado pueda ser sometido a decisión de todo el país, pues, además de ser inoficioso, los pobladores del resto del país no tienen derecho a pronunciarse sobre un asunto que, por disposición constitucional, no les compete.

Cabe señalar también que este límite a la consulta popular ha sido reconocido a nivel internacional, pues la jurisprudencia comparada ha señalado que, si bien "dentro del marco de la democracia participativa, la consulta popular es un mecanismo idóneo para que la ciudadanía decida, a través de una respuesta afirmativa o negativa, sobre asuntos nacionales, departamentales, municipales, distritales o locales", "dependiendo del nivel a tratar, la consulta se encuentra limitada por el reparto de competencias establecidas en la Constitución y en la Ley" (énfasis añadido). ${ }^{61}$

Ahora bien, pese a que el régimen de competencias impone un límite claro al alcance territorial y material de las consultas populares, la jurisprudencia de la Corte Constitucional ha sido bastante flexible en cómo ha entendido los "temas de interés para su jurisdicción" en el contexto de los gobiernos autónomos descentralizados. En el dictamen No. 6-20-CP/20, en el que analizó la constitucionalidad de la solicitud de consulta popular propuesta por el Concejo Municipal de Cuenca sobre la prohibición de actividades mineras a gran y mediana escala en cinco zonas de recarga hídrica de dicho cantón, la Corte Constitucional señaló lo siguiente:

59 El régimen de competencias está previsto en el capítulo cuarto del título V de la Constitución, referente a la organización territorial del Estado.

60 Rafael Oyarte, Derecho Constitucional, 436.

61 Sentencia No. SU095/18, Corte Constitucional de Colombia, 11 de octubre de 2018. 
[S]e debe empezar precisando que de conformidad con el inciso tercero del artículo 104 de la CRE, cuando una consulta proviene de la iniciativa de los GADs esta puede versar "sobre temas de interés para su jurisdicción". Así, este Organismo constitucional ha señalado que los temas de interés para la jurisdicción tienen un espectro amplio, pues su restricción a temas "que sean de competencia del correspondiente nivel de gobierno" introducida en la reforma constitucional del 2015, fue declarada inconstitucional y no se halla vigente (énfasis ańadido). ${ }^{62}$

Llama la atención que el argumento que la Corte emplea para realizar una interpretación amplia de la frase "sobre los temas de interés para su jurisdicción" sea la inconstitucionalidad de la frase "que sean de competencia del correspondiente nivel de gobierno", declarada en la sentencia No. 018-18-SIN-CC, pues dicha inconstitucionalidad fue declarada exclusivamente por la forma en la tramitación de las enmiendas constitucionales del año $2015 .{ }^{63}$ Por lo tanto, la Corte Constitucional nunca determinó - como se alegó en una de las demandas de inconstitucionalidad presentadas ${ }^{64}$ — que se restringen los derechos a ser consultados y a participar en asuntos de interés público al exigir que los temas sometidos a consulta popular por parte de los gobiernos autónomos descentralizados sean de su competencia. Simplemente parecería ser que, al ańadir esta frase, se reconoció de forma expresa un límite a la consulta popular que ya se encontraba implícito en el texto constitucional.

Por otro lado, la Corte Constitucional también ha considerado que el artículo 260 de la Constitución justifica una interpretación amplia de la frase "temas de interés para la jurisdicción" de los gobiernos autónomos descentralizados, al señalar que:

Esta iniciativa de participación de las comunidades locales mediante la consulta popular puede provenir no solo de la propia ciudadanía, sino también de los gobiernos autónomos descentralizados, sobre temas de interés para su jurisdicción, sin que ello signifique automáticamente violar las competencias del Estado central. En efecto, la Constitución expresa y claramente determina en su artículo 260 que "el ejercicio de las competencias exclusivas no excluirá el ejercicio concurrente de la gestión en la prestación de servicios públicos y actividades de colaboracion y complementariedad entre los distintos niveles de gobierno" (énfasis añadido). ${ }^{65}$

En este contexto y refiriéndose a las consultas populares en materia de minería, la Corte consideró que "existen competencias relacionadas y actividades de colaboración y complementariedad de los gobiernos autónomos descentralizados que necesariamente inciden sobre la gestión de los recursos minerales

62 Dictamen No. 6-20-CP/20, Corte Constitucional del Ecuador, 18 de septiembre de 2020, párr. 53.

63 Sentencia No. 018-18-SIN-CC, Corte Constitucional del Ecuador, 01 de agosto de 2018.

64 Ver la demanda presentada dentro del caso No. 0099-15-IN, resumida en las páginas 19-21 de la sentencia No. 018-18-SIN-CC.

65 Dictamen No. 9-19-CP/19, Corte Constitucional del Ecuador, 17 de septiembre de 2019, párr. 41. 
por parte del Estado central" ${ }^{66}$ Este fue uno de los argumentos para que la Corte admita la posibilidad de realizar consultas populares locales sobre asuntos de interés nacional y de competencia exclusiva del gobierno central, como lo son los recursos naturales no renovables, entre los cuales se encuentran los minerales. ${ }^{67}$

Una interpretación sistemática de la Constitución exige que el artículo 260 de la Constitución no pueda ser interpretado de manera que vacíe de contenido las normas que asignan competencias exclusivas a cada nivel de gobierno. Para comprender el alcance de esta norma, entonces, es necesario recurrir a las definiciones de "gestión" y "complementariedad" a las que se refiere el artículo 260, y que están establecidas en el Código Orgánico de Organización Territorial, Autonomía y Descentralización (en adelante COOTAD).

Respecto de la gestión, el inciso final del artículo 116 del COOTAD señala que esta consiste en "la capacidad para ejecutar, proveer, prestar, administrar y financiar servicios públicos". ${ }^{68} \mathrm{El}$ "ejercicio concurrente de la gestión en la prestación de servicios públicos" a la que se refiere el artículo 260 de la CRE, entonces, implica que los diferentes niveles de gobierno puedan coordinar acciones en torno a la prestación, administración y financiamiento de un servicio público, con el fin de garantizar la mayor satisfacción posible de los usuarios del servicio. Respecto de la complementariedad, el artículo 3 letras c) y e) del COOTAD prescribe que se incentiva la coordinación y el trabajo complementario y articulado entre los diferentes niveles de gobierno, con el fin de promover el ejercicio de los derechos de las personas y el buen vivir, siempre "en el marco de las competencias exclusivas y concurrentes de cada uno de ellos" ${ }^{69}$ Así, incluso en aquello que requiera una gestión complementaria entre los diferentes niveles de gobierno y que, por lo tanto, ya no sería solamente de interés de uno de ellos, el ámbito de dicha gestión estaría limitada por la existencia de las competencias exclusivas establecidas en la Constitución, las cuales bajo ningún concepto podrían ser desconocidas o anuladas.

En el caso de la consulta popular sobre temas mineros a la que se hizo referencia, la propuesta de consulta popular ni siquiera se orientaba —ni justificaba la existencia- de una actividad que requiera de complementariedad o de una gestión concurrente por parte de distintos niveles de gobierno. Al contrario, se enfocaba en el derecho a participar en asuntos de interés público y solicitaba que se incluya una nueva prohibición a la realización de actividades mineras, exclusivamente en la provincia del Azuay, ${ }^{70}$ lo cual, en nuestro criterio, desconoce abiertamente el régimen de competencias, según el cual los recursos

66 Ibid., párr. 43.

67 Artículo 261, Constitución de la República del Ecuador.

68 Artículo 116, Código Orgánico de Organización Territorial, Autonomía y Descentralización [COOTAD]. R.O. Suplemento 303 de 19 de octubre de 2010.

69 Id., Artículo 3 letra c).

70 Dictamen No. 9-19-CP/19, Corte Constitucional del Ecuador, 17 de septiembre de 2019, párr. 7. 
naturales no renovables son competencia exclusiva del Estado central y pertenecen a todo el Estado ecuatoriano. ${ }^{71}$

En el dictamen No. 6-20-CP/20, a pesar de que la Corte Constitucional se refirió expresamente al régimen de competencias, llama la atención que no lo analizó como un factor que incide en la constitucionalidad de las preguntas, sino en la constitucionalidad de las "medidas a adoptar" una vez que la consulta popular ha sido realizada. ${ }^{72}$ Coincidimos con la Corte en que no cabe duda de que si la implementación del resultado de una consulta popular requiere de la intervención de distintos niveles de gobierno, estos deberán actuar en el marco de sus competencias y de forma complementaria. Aquello, sin embargo, implicaría un control ex post de las "medidas a adoptar", lo cual es distinto del control previo de constitucionalidad, que debería tener por objeto determinar si el asunto o materia sometido a consideración de una determinada circunscripción territorial es competencia exclusiva de dicho nivel de gobierno. En nuestro criterio, la complementariedad prevista constitucionalmente -que debe existir entre todos los niveles de gobierno- no implica que un nivel de gobierno pueda asumir una competencia que por disposición constitucional le corresponde a otro. Simplemente podría colaborar en la ejecución de la decisión adoptada por el nivel de gobierno competente, siempre en armonía con las competencias que le han sido constitucionalmente otorgadas.

En definitiva, con el fin de evitar la exclusión injustificada de ciertas personas o grupos de personas del proceso democrático, es muy importante que las consultas populares locales se limiten a aquello que es competencia del correspondiente nivel de gobierno. Ello no implica que no existan ciertas circunstancias en que se requiera de una gestión concurrente y complementaria entre los diferentes niveles de gobierno, pero aquello deberá ser cuidadosamente evaluado por la Corte Constitucional a través del control de constitucionalidad, bajo los términos del COOTAD y sobre la base del régimen de competencias establecido en la CRE.

Finalmente, es importante aclarar que este respeto al régimen de competencias no significa que este no pueda ser modificado mediante una enmienda constitucional, que puede ser realizada mediante referéndum, conforme el artículo 441 numeral 1 de la Constitución. Sin embargo, mientras aquello no ocurra, la existencia de competencias exclusivas establecidas en la Constitución marca un claro límite territorial y material a las consultas populares.

71 Artículo 1, Constitución de la República del Ecuador.

72 " $[\mathrm{E}] \mathrm{n}$ este plebiscito, para que las medidas a adoptarse, en caso de obtener un resultado positivo, sean constitucionales deben estar enmarcadas en el ámbito competencial de cada nivel de gobierno [...] y su implementación debe efectuarse de forma coordinada y complementaria, observando también lo prescrito en el artículo 425 de la CRE, que establece el orden jerárquico de aplicación de las normas". Dictamen No. 6-20-CP/20, Corte Constitucional del Ecuador, 18 de septiembre de 2020, párr. 68 . 


\subsection{LA CONSULTA POPULAR NO PUEDE REEMPLAZAR OTROS PROCEDIMIENTOS ESTABLECIDOS EN LA CONSTITUCIÓN NI MODIFICAR EL TEXTO CONSTITUCIONAL}

Otros límites que consideramos intrínsecos de la consulta popular son los demás tipos de consulta previstos en la Constitución y el propio contenido de la CRE, que no podrá ser modificado sino por los procedimientos de modificación constitucional previstos en la misma Constitución. A continuación, nos referiremos a cada uno de estos límites.

\subsubsection{LA CONSULTA POPULAR NO PUEDE REEMPLAZAR A LOS OTROS TIPOS DE CONSUlTA PREVISTOS EN LA CONSTITUCIÓN}

La consulta popular no es el único tipo de consulta previsto en la Constitución, pues la CRE reconoce también a la consulta previa, a la consulta prelegislativa y a la consulta ambiental. Para determinar el alcance de los otros tipos de consulta, analizaremos cada una según lo establecido en el texto constitucional y en la jurisprudencia de la Corte Constitucional y sostendremos que, para que las normas que reconocen dichas consultas no queden vacías de contenido, la consulta popular no puede reemplazar estos mecanismos de participación.

La diferenciación entre los demás tipos de consulta y la consulta popular ya fue realizada por las juezas constitucionales Nuques y Corral, en su voto concurrente dentro del caso No. 9-19-CP. Frente al voto de mayoría que sostuvo que los diferentes tipos de consulta previstos en la CRE "coexisten entre sî", ${ }^{73}$ las juezas Nuques y Corral justificaron la necesidad de delimitar el alcance de cada tipo de consulta en la medida de que "si bien todos los tipos de consulta devienen del derecho de participación de los ciudadanos en asuntos públicos, no pueden equipararse con la consulta popular [...]", ${ }^{74}$ pues "[l] os elementos, efectos y el procedimiento de cada una de estas formas de participación en asuntos públicos, son diferentes". ${ }^{75}$

La consulta previa está reconocida en el artículo 57 numeral 7 de la Constitución como un derecho colectivo de las comunas, comunidades, pueblos y nacionalidades indígenas a ser consultados, de manera obligatoria, oportuna y dentro de un plazo razonable, sobre los "planes y programas de prospección, explotación y comercialización de recursos no renovables que se encuentren en sus tierras y que puedan afectarles ambiental o culturalmente". ${ }^{76}$ La Corte Constitucional, sobre la base del Convenio 169 de la Organización Interna-

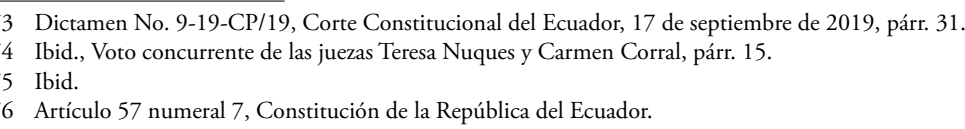


cional del Trabajo, ha enfatizado en el hecho de que la consulta previa no es "un mero trámite formal o informativo", ${ }^{77}$ sino que es un verdadero mecanismo de participación que es responsabilidad del Estado implementar, con el fin de que los pueblos y comunidades indígenas puedan "influir de manera significativa en el proceso y en las decisiones tomadas en el mismo". ${ }^{78}$

La consulta prelegislativa también está reconocida como un derecho colectivo de las comunas, comunidades, pueblos y nacionalidades indígenas y consiste en el derecho a "ser consultados antes de la adopción de una medida legislativa que pueda afectar cualquiera de sus derechos colectivos".$^{79}$ La Corte Constitucional ha diferenciado a la consulta prelegislativa de la consulta previa, pues ha señalado que la primera procede en todos los casos de actos normativos que no se enmarquen en las hipótesis en las que cabe la consulta previa, es decir, en aquello relacionado con planes y programas de prospección, explotación y comercialización de recursos no renovables. ${ }^{80}$ Incluso, la Corte ha determinado que la consulta prelegislativa procede "siempre y cuando, para la emisión de dicho acto [emanado de cualquier autoridad pública con potestad normativa y que pueda afectar derechos colectivos], no exista una forma específica de consulta, tal como la consulta previa". ${ }^{81}$

Así como la Corte ha reconocido que la consulta previa y la consulta prelegislativa tienen alcances distintos, es preciso también distinguir a ambos mecanismos de la consulta popular. La diferencia fundamental entre ambas figuras y la consulta popular es que esta no es un derecho colectivo, exclusivo de las comunas, comunidades, pueblos y nacionalidades indígenas. Justamente por ser un derecho colectivo, existen ciertas consecuencias derivadas de la falta de consulta previa o prelegislativa que no existen en el caso de la consulta popular. En el caso de que no se haya realizado una consulta prelegislativa, la Corte Constitucional ha señalado que aquello puede acarrear una inconstitucionalidad por la forma - por existir una omisión en el procedimiento legislativo- así como una inconstitucionalidad por el fondo, por vulnerar un derecho constitucional. ${ }^{82}$ En cuanto a la consulta previa, la Corte ha señalado que el incumplimiento de esta obligación estatal podría acarrear responsabilidad para el Estado a nivel internacional, así como "la eventual nulidad de los procedimientos y medidas adoptadas". ${ }^{83}$ La consulta popular, además de no ser un derecho colectivo, tiene entonces un contenido distinto de estos otros tipos de consulta: (i) no implica una obligación de consultar, sino una facultad de hacerlo y una obligación de acatar el pronunciamiento popular una vez

\footnotetext{
Sentencia No. 20-12-IN/20, Corte Constitucional del Ecuador, 1 de julio de 2020, párr. 77.

Ibid.

79 Artículo 57 numeral 17, Constitución de la República del Ecuador.

80 Sentencia No. 20-12-IN/20, Corte Constitucional del Ecuador, 1 de julio de 2020, párr. 82.

81 Ibid., párr. 93.

82 Ibid., párr. 99.

83 Sentencia No. 001-10-SIN-CC, Corte Constitucional del Ecuador, 18 de marzo de 2010, p. 55.
} 
desarrollada la consulta; ${ }^{84}$ y (ii) no se circunscribe a la adopción de medidas legislativas o administrativas, ni a los planes y programas de prospección, explotación y comercialización de recursos no renovables. Las diferencias entre estas figuras impiden que la consulta popular pueda superponerse a la consulta previa y prelegislativa; caso contrario, no tendría utilidad alguna el hecho de que la CRE haya reconocido a estas últimas como derechos colectivos con alcances distintos.

Por otra parte, la consulta ambiental está reconocida en el artículo 398 de la CRE, que prescribe que " $\mathrm{t}$ ] oda decisión o autorización estatal que pueda afectar al ambiente deberá ser consultada a la comunidad, a la cual se informará amplia y oportunamente" ${ }^{85}$ Esta consulta implica, entonces, un deber de información por parte del Estado hacia una comunidad potencialmente afectada por una decisión estatal en materia ambiental, así como la necesidad de valorar el criterio de la comunidad respecto de dicha decisión. A diferencia de la consulta previa y prelegislativa, la consulta ambiental no es un derecho colectivo de las comunidades, pueblos y nacionalidades indígenas y, por lo mismo, es aplicable en el caso de cualquier comunidad que pueda verse afectada por una decisión estatal en materia ambiental. ${ }^{86}$ Por otro lado, la consulta ambiental se diferencia de la consulta popular, pues no implica un proceso de sufragio y carece de efectos vinculantes. ${ }^{87}$ Así, de acuerdo con el propio artículo 398, en caso de que la mayoría de la comunidad se oponga a la realización del proyecto que podría causar una afectación al ambiente, la decisión deberá ser adoptada por "resolución debidamente motivada de la instancia administrativa superior". ${ }^{88}$ Por lo expuesto, es claro que ambas figuras tienen efectos y alcances diferentes y que una consulta popular no podría ser utilizada para desconocer o sustituir el contenido de la consulta ambiental.

Un ejemplo de un pedido de consulta popular que, en nuestro criterio, confundió el alcance de este mecanismo de participación con la consulta ambiental, fue aquella tratada por la Corte Constitucional en el dictamen No. 9-19$\mathrm{CP} / 19$. En la exposición de motivos, el proponente citó el artículo 104 de la CRE, referente a la consulta popular, e inmediatamente después citó el artículo 398, referente a la consulta ambiental. ${ }^{89}$ Además, en los consideran-

84 Artículo 106, Constitución de la República del Ecuador

85 Artículo 398, Constitución de la República del Ecuador.

86 Así lo estableció la Corte Constitucional en la sentencia No. 001-10-SIN-CC, en la que justamente diferenció a la consulta ambiental de la consulta previa, exclusiva de las comunidades, pueblos y nacionalidades indígenas. Sentencia No. 001-10-SIN-CC, Corte Constitucional del Ecuador, 18 de marzo de 2010, p. 112.

87 En materia minera, de acuerdo con la sentencia No. 001-10-SIN-CC, la consulta ambiental está reconocida en los artículos 88 y siguientes de la Ley de Minería y, justamente por tratarse de este tipo de consulta, no aplica a las comunidades, pueblos y nacionalidades indígenas. De acuerdo con el artículo 89 de la Ley de Minería, el objetivo de este proceso de participación es "considerar e incorporar los criterios de la comunidad en la gestión social y ambiental de un proyecto minero". Sin perjuicio de lo indicado, cabe seńalar que la Corte Constitucional se pronunciará sobre el alcance de la consulta ambiental en, al menos, dos casos que se están sustanciado de forma paralela: caso No. 2436-19-EP y caso No. 1149-19-JP.

88 Artículo 398, Constitución de la República del Ecuador.

89 Ver la demanda presentada el 30 de julio de 2019 dentro del caso No. 0009-19-CP. 
dos, el proponente fundamentó la solicitud de consulta popular en que "es un derecho constitucional que el Estado garantice la participación activa y permanente de las personas, comunidades, pueblos y nacionalidades afectadas, en la planificación, ejecución y control de toda actividad que genere impactos ambientales [...]". ${ }^{90}$ Es claro que en esta solicitud se pretendió obtener un pronunciamiento vinculante (consulta popular) sobre un asunto que está cobijado específicamente por la consulta ambiental. Aquello constituye una lectura asistemática de la CRE que vacía de contenido al artículo 398 de la Constitución y que entiende que el derecho a ser consultados carece de límites.

Sin perjuicio de lo indicado, es importante señalar que las diferencias y los alcances distintos de cada uno de los mecanismos de participación que se han mencionado no significan que estos tipos de consulta previstos en la Constitución no "coexistan entre si". Al contrario, justamente porque todos estos mecanismos de participación están previstos en la Constitución y coexisten, no pueden ser sustituidos por la consulta popular, so pena de desconocer su contenido.

\subsubsection{LA CONSULTA POPULAR NO PUEDE TENER UN CONTENIDO CONTRaRio a la CONSTITUCIÓN, DE MANERA QUE IMPLIQUE UNA MODIFICACIÓN CONSTITUCIONAL}

La jurisprudencia de la Corte Constitucional ha sido consistente en que, a través de la consulta popular prevista en el artículo 104 de la CRE, no se puede modificar el contenido del texto constitucional. Sobre la base de una lectura sistemática de la Constitución, la Corte ha sido clara en cuanto a que la propia CRE establece los mecanismos idóneos para su modificación: la enmienda, la reforma parcial y la Asamblea Constituyente. Así, la Corte ha señalado que:

la modificación del texto constitucional solo puede realizarse por medio de los mecanismos regulados en los artículos 441, 442 y 444 de la Constitución. La consulta popular ordinaria [...] regulada por el artículo 104 de la Constitución, no es uno de los mecanismos previstos para la reforma constitucional. A través del procedimiento de consulta popular ordinaria no es posible efectuar cambio constitucional alguno" (énfasis ańadido). ${ }^{91}$

En este mismo sentido, en un caso en que la solicitud de consulta popular tenía por objeto suprimir el Consejo de Participación Ciudadana y Control Social así como el Tribunal Contencioso Electoral, la Corte consideró que la

90 Dictamen No. 9-19-CP/19, Corte Constitucional del Ecuador, 17 de septiembre de 2019, párr. 7.

91 Dictamen No. 4-19-CP/19, Corte Constitucional del Ecuador, 01 de agosto de 2019, párr. 14. 
propuesta implicaba un cambio del texto constitucional y señaló que "acudir al mecanismo de consulta popular, en reemplazo de las figuras constitucionales idóneas —enmienda, reforma o cambio-, constituiría un fraude a la propia Constitución”, aún cuando estos mecanismos de reforma constitucional puedan incluir la realización de un referéndum aprobatorio. ${ }^{92}$ Coincidimos plenamente con la Corte en cuanto a que se comete un fraude constitucional al utilizar la consulta popular con el fin de eludir los mecanismos previstos en la propia Constitución para la modificación de su texto, y cuya finalidad es garantizar la supremacía constitucional. ${ }^{33}$

Sin embargo, aunque este límite a la consulta popular ha sido claramente identificado por la Corte Constitucional, han existido discrepancias en cuanto a su aplicación, sobre todo en casos complejos como los relacionados con consultas populares sobre minería (particularmente, consultas populares cuyo objetivo ha sido prohibir actividades mineras en determinadas circunscripciones territoriales). El argumento principal para sostener la improcedencia de las consultas populares sobre minería es que el artículo 407 de la Constitución ya establece, de manera taxativa, cuáles son las áreas y zonas en las que se prohíbe realizar actividades mineras. ${ }^{94}$ Siendo la minería una actividad lícita que se ampara en el derecho a ejercer actividades económicas, para incluir una nueva prohibición para el ejercicio de dicha actividad, se debería modificar el contenido del artículo 407 de la CRE. ${ }^{95} \mathrm{La}$ Corte Constitucional, en los votos de mayoría dentro de los casos No. 6-20-CP/20 y 9-19-CP/19, no analizó dicho argumento desde la óptica de la modificación constitucional y la consulta popular. En ambos dictámenes, la Corte se limitó a señalar que no existe una disposición constitucional "que prohíba clara y expresamente que la ciudadanía pueda plantear como asunto de consulta popular" temas relacionados con actividades mineras. ${ }^{96} \mathrm{Si}$ bien este razonamiento busca precautelar la eficacia de la consulta popular, tampoco puede ser invocado de manera absoluta, desconociendo la existencia de normas constitucionales que contienen límites implícitos a la consulta popular, pues de hacerlo, aquello implicaría brindar un tratamiento asistemático y aislado de la consulta popular, así como del contenido de la CRE, lo cual no es aceptable de acuerdo con el artículo 427 de la Constitución.

A diferencia de los votos de mayoría en ambos casos, las juezas Nuques y Corral, en sus votos salvados y concurrentes en los casos relacionados con con-

92 Dictamen No. 6-19-CP/19, Corte Constitucional del Ecuador, 01 de agosto de 2019, párr. 33.

93 En este sentido se ha pronunciado la Corte Constitucional en el dictamen No. 4-19-CP/19 (párr. 17).

94 Juan Francisco Guerrero del Pozo, "Consultas populares sobre minería: un fraude constitucional”, Miner News Cámara de Minería del Ecuador 1 (Septiembre 2020): http://cme.org.ec/wp-content/uploads/2020/11/Consultas-Populares.pdf

$95 \mathrm{El}$ argumento se fundamenta, además, en que en el Ecuador ya existió un antecedente respecto de cuál es la vía para limitar la actividad minera en zonas no previstas en el artículo 407 de la Constitución. Dicho antecedente es la enmienda constitucional promovida por el Presidente de la República en febrero del año 2018.

96 Dictamen No. 9-19-CP/19, Corte Constitucional del Ecuador, 17 de septiembre de 2019, párr. 21. 
sultas populares sobre minería, sí definieron el alcance del artículo 407 de la Constitución respecto de la consulta popular y consideraron que el contenido de esta norma imponía un límite a lo que podía ser objeto de pronuciamiento de la ciudadanía a través de este mecanismo de participación. ${ }^{97}$

Un "caso complejo" como el de las consultas populares sobre minería, refleja los criterios dispares que existen dentro de la Corte sobre el alcance del límite que el propio contenido de la Constitución impone a la consulta popular. Lo que resulta necesario es que la Corte realice un análisis profundo de las normas constitucionales que podrían verse alteradas o modificadas de alguna forma por la consulta popular y emita un pronunciamiento contundente al respecto en sus dictámenes previos de constitucionalidad. Solo cuando exista dicho análisis pormenorizado, será aceptable un argumento que sostenga que "no existe prohibición constitucional" para realizar consultas populares sobre determinada materia.

\section{El rol de la Corte Constitucional en materia de CONSULTAS POPULARES: LA IMPORTANCIA DE LOS DICTÁMENES PREVIOS DE CONSTITUCIONALIDAD}

A lo largo de este trabajo hemos sido enfáticos en la importancia de los dictámenes previos de constitucionalidad de las solicitudes de consulta popular, a través de los cuales la Corte Constitucional controla que se respeten los límites de este mecanismo de participación ciudadana. Por esa razón, el artículo 104 de la CRE exige que en todos los casos las consultas populares deban contar con el dictamen previo de constitucionalidad de la Corte Constitucional. A pesar de la claridad del texto constitucional, la facultad de la Corte para controlar la constitucionalidad de las consultas populares ha sido limitada por el inciso final del artículo 105 de la Ley Orgánica de Garantías Jurisdiccionales y Control Constitucional (en adelante LOGJCC). A continuación, analizaremos brevemente este artículo y recomendaremos la declaratoria de inconstitucionalidad de la referida norma, con el fin de que, en todos los casos, la Corte pueda controlar los límites materiales de la consulta popular que han sido identificados en este trabajo, así como los límites formales relacionados con la libertad del elector. ${ }^{98}$

97 Ver voto salvado de las juezas Nuques y Corral dentro del caso No. 6-20-CP/20, así como los votos concurrentes, entre otros, dentro de los casos No. 9-19-CP/19 y 1-20-CP/20.

98 La Corte Constitucional ha señalado que, a través de los dictámenes previos de constitucionalidad, realiza un control formal y un control material de las consultas populares, sobre la base de los parámetros contenidos en los artículos 104 y 105 de la LOGJCC. La Corte ha sostenido que "[a]mbos tipos de control persiguen [...]: el examen formal, la finalidad de garantizar la libertad del elector; y el examen material, la constitucionalidad de "las disposiciones jurídicas" o de las "medidas a adoptar”, según corresponda a un referéndum o a un plebiscito”. Dictamen No. 5-20-CP/20, Corte Constitucional del Ecuador, 26 de agosto de 2020, párr. 12. 
El inciso final del artículo 105 de la LOGJCC, incluido en la LOGJCC con motivo del control constitucional de las enmiendas y reformas constitucionales, es aplicable por remisión expresa de la ley ${ }^{99}$ a las consultas populares y prescribe lo siguiente:

Si la Corte Constitucional no resolviere sobre la convocatoria, los considerandos y el cuestionario del referendo, dentro del término de veinte días siguientes a haber iniciado el respectivo control previo, se entenderá que ha emitido dictamen favorable. Esta omisión dará lugar a las sanciones administrativas que correspondan (énfasis añadido). ${ }^{100}$

De acuerdo con esta norma, entonces, si la Corte Constitucional no se pronuncia respecto de la constitucionalidad de la solicitud de consulta popular dentro de cierto tiempo, existirá un dictamen "ficto" de constitucionalidad que será favorable a la consulta. Este límite temporal para el ejercicio de la competencia de control de constitucionalidad de las consultas populares ha sido entedido por la jurisprudencia de la Corte Constitucional ${ }^{101}$ y por cierta doctrina ${ }^{102}$ como un mecanismo para evitar que los derechos de participación de los ciudadanos — en particular el derecho a ser consultados- sean coartados por la inactividad de la Corte Constitucional. Sin embargo, en nuestro criterio, no se puede sostener que los derechos de participación se garantizan cuando se pone a consideración de la ciudadanía un texto que es materialmente inconstitucional o que no permite que el elector tome una decisión libre e informada.

Al contrario, consideramos que el dictamen "ficto" introducido por el artículo 105 de la LOGJCC constituye un mecanismo para evitar el control de constitucionalidad y parte de la premisa - errónea- de que un texto que es inconstitucional podría adecuarse a la Constitución por el mero paso del tiempo. Además de contrariar el contenido del artículo 104 de la CRE — que no admite excepciones respecto del control previo de constitucionalidad de las consultas populares - la vigencia del artículo 105 de la LOGJCC implica que, transcurrido el término previsto en dicha norma, se podrían considerar constitucionales eventuales decisiones que anulen o restrinjan injustificadamente los derechos de las personas, que desconozcan el régimen de competencias, que vacíen de contenido a los demás mecanismos de participación previstos en la CRE o, incluso, que modifiquen el contenido de la Constitución. En otras palabras, la vigencia de esta norma legal puede acarrear que las normas constitucionales que prevén los límites a la consulta popular que han

99 Artículo 127, Ley Orgánica de Garantías Jurisdiccionales y Control Constitucional [LOGJCC]. R.O. Suplemento 52 de 22 de octubre de 2009.

100 Id., Artículo 105.

101 Ver Caso No. 0001-17-CP, Corte Constitucional del Ecuador, 18 de marzo de 2019, párr. 14

102 Ver Sebastián López Hidalgo, "El control de constitucionalidad de las convocatorias a consultas populares en la Corte Constitucional ecuatoriana”, Ius Constitutionale. Revista de Derecho Constitucional No. 1 (enero-abril 2021): 190-191. 
sido identificados en este trabajo queden vacías de contenido, lo cual, evidentemente, vulnera la supremacía constitucional.

Por todo lo expuesto, consideramos que es necesario que la Corte Constitucional declare la inconstitucionalidad del inciso final del artículo 105 de la LOGJCC y que, en todos los casos, realice un estricto control de constitucionalidad de las consultas populares, con el fin de que se respeten los límites intrínsecos de esta figura, que se desprenden de una lectura sistemática de la CRE.

\section{Conclusiones}

Es indudable la importancia que la Constitución de 2008 le otorga a la participación ciudadana. Uno de los mecanismos más poderosos para que la ciudadanía pueda ejercer su derecho a participar en asuntos de interés público es la consulta popular, reconocida en el artículo 104 de la CRE. Esta figura tiene un amplio alcance en la Constitución ecuatoriana, sin que sus límites se desprendan claramente de una lectura del artículo 104. Por esa razón, en esta investigación se han identificado ciertos límites materiales - explícitos e implícitos- de la consulta popular, que son el resultado de una interpretación sistemática de la Constitución.

Así, se ha determinado que un primer límite intrínseco a la consulta popular es el contenido esencial de los derechos fundamentales y que, en tal sentido, es posible regular el ejercicio de los derechos constitucionales a través de este mecanismo de participación, siempre que aquello no anule o desnaturalice el derecho en cuestión.

Un segundo límite intrínseco a la consulta popular es el régimen de competencias previsto en la CRE que, de no ser respetado, puede: (i) excluir injustificadamente del proceso democrático a quienes tienen derecho a pronunciarse sobre el tema consultado; (ii) incluir en el proceso democrático a quienes no deben pronunciarse sobre un determinado asunto; $y$, evidentemente, (iii) vaciar de contenido a las competencias exclusivas previstas expresamente en la CRE a favor de cada nivel de gobierno.

El tercer límite a la consulta popular son los demás procedimientos previstos en la Constitución, lo cual incluye a los otros tipos de consulta establecidos en la CRE y al propio contenido de la Constitución, que no podrá ser modificado sino por una enmienda, reforma parcial o Asamblea Constituyente. Constituiría un fraude constitucional que la consulta popular prevista en el artículo 104 de la Constitución pueda reemplazar y desconocer el contenido de estos otros procedimientos previstos en la propia CRE, que tienen alcances y objetivos distintos a la consulta popular. 
Finalmente, es importante recalcar que el respeto de estos límites debe ser, en todos los casos, objeto de un riguroso control de constitucionalidad por parte de la Corte Constitucional, desechando la posibilidad de un dictamen ficto que resulta muy peligroso. A pesar de que existen todavía criterios dispares dentro de la Corte - sobre todo en los casos de mayor polémica- es importante que la Magistratura siempre realice un análisis pormenorizado y claro sobre los límites de la consulta popular que han sido identificados en este trabajo. Solo a través del estricto control de constitucionalidad previo por parte de la Corte Constitucional, se podrá evitar la distorsión y mala utilización de este importante mecanismo de participación previsto en nuestra Constitución. 
